Abstracta Iranicacta Iranica

Revue bibliographique pour le domaine irano-aryen

Volume 32-33 | 2013

Comptes rendus des publications de 2009-2010

\title{
Christopher H. Roosevelt. The Archaeology of Lydia, from Gyges to Alexander
}

\section{Rémy Boucharlat}

\section{(2) OpenEdition}

1 Journals

Édition électronique

URL : http://journals.openedition.org/abstractairanica/40410

DOI : 10.4000/abstractairanica.40410

ISSN : 1961-960X

\section{Éditeur :}

CNRS (UMR 7528 Mondes iraniens et indiens), Éditions de l'IFRI

\section{Édition imprimée}

Date de publication : 1 décembre 2013

ISSN : 0240-8910

\section{Référence électronique}

Rémy Boucharlat, «Christopher H. Roosevelt. The Archaeology of Lydia, from Gyges to Alexander », Abstracta Iranica [En ligne], Volume 32-33 | 2013, document 114, mis en ligne le 01 juillet 2016, consulté le 30 septembre 2020. URL : http://journals.openedition.org/abstractairanica/40410; DOI : https://doi.org/10.4000/abstractairanica.40410

Ce document a été généré automatiquement le 30 septembre 2020.

Tous droits réservés 


\title{
Christopher H. Roosevelt. The Archaeology of Lydia, from Gyges to Alexander
}

\author{
Rémy Boucharlat
}

\section{RÉFÉRENCE}

Christopher H. Roosevelt. The Archaeology of Lydia, from Gyges to Alexander. New York, Cambridge University Press, 2009, 314 p., index., env. 100 ill.

1 Publication d'une dissertation soutenue en 2003. Le sujet est l'archéologie de la Lydie, une recherche que G.M.A. Hanfmann, fondateur de l'actuel projet Sardes appelait de ses vœux trente ans plus tôt. Même si beaucoup reste à faire, dit l'A., cette étude régionale est de celles dont on aimerait disposer pour bien des villes de l'époque achéménide - et d'autres périodes, ce qui est entrepris en Mésopotamie depuis des années. De ce riche royaume, qui fut en relation avec les rois assyriens, mèdes, égyptiens et les cités grecques d'Asie Mineure, on connaît des pans d'histoire, dès la fin du VIII ${ }^{\mathrm{e}}$ s. av. J.-C. époque de l'indépendance, jusqu'à l'époque achéménide, lorsque Cyrus prit le dessus sur le roi Crésus. Cinquante-cinq ans de fouilles ont mis au jour des témoins nombreux et riches des réalisations dans la ville de Sardes. Pour celle-ci, on dispose pour la période achéménide de l'essai synthétique de E. Dussinbere, Aspects of Empire in Achaemenid Sardis, 2003 (cf. Abs. Ir. 26, $\mathrm{n}^{\circ}$ 96). Les deux ouvrages se complètent, et c'est largement ce qui fait l'intérêt de l'un et de l'autre.

$2 \mathrm{CR}$, qui a prospecté lui-même les environs de Sardes, a rassemblé les données archéologiques éparses, certaines inédites, que les objets soient conservés à Sardes ou dans les musées de Turquie. Ce matériel est remis dans le contexte géographique et environnemental, faisant appel aux données géographiques anciennes. Il analyse la répartition des habitats et des tombes (c'est le pays des grands tumuli), dans ce qu'il appelle la Grande Lydie, par opposition à la Lydie centrale, située entre Sardes et le lac 
Gygès. Dans une telle étude, il prend en considération la région et la ville de Sardes même en tant que composante de l'occupation de la région. C'était le bon choix, mais fallait-il aller jusqu'à consacrer un chapitre spécifique à Sardes (chap. 4 'Settlement and Society in Sardis') ? Les redondances avec l'ouvrage de E. Dussinbere sont, là surtout mais ailleurs aussi, nombreuses, tant pour les monuments que les inscriptions et le matériel; des renvois précis du premier au second étaient envisageables. Il reste que l'extension de l'enquête à la région permet de proposer un éventail plus important des types, qu'il s'agisse des tombes, de la sculpture ou bas-reliefs, et par là une vision élargie au royaume. Cette diversité apparaît bien dans le catalogue de 50 pages qui donne pour chaque site une description de quelques lignes et une bibliographie.

3 Cet ouvrage, qui reste un peu général du fait de son format, est bien renseigné et riche d'observations et d'hypothèses. Souhaitons qu'il stimule nombre d'archéologues à construire un programme spécifique d'étude de la région qui entoure le site qu'ils fouillent, puis - et surtout, ce qui est trop rare - à en publier les résultats en parallèle à ceux obtenus sur le site.

\section{AUTEURS}

\section{RÉMY BOUCHARLAT}

CNRS, Lyon 